\title{
How to Motivate Students in Large-enrollment Courses for Active-learning
}

\section{Radka High $^{1}$, Karolina Duschinská ${ }^{2}$}

${ }^{1}$ Department of Psychology, Faculty of Education, Charles University, Czech Republic, ${ }^{2}$ Department of Education, Faculty of Education, Charles University, Czech Republic.

\begin{abstract}
Large-enrollment courses are often necessary platforms for teaching in universities all over the world. This article will begin with a theoretical approach in which we introduce proofs from cognitive psychology that demonstrate the effectiveness of active learning methods over the more traditional structured, lecture based, lessons. Second part consists of analysis of our lectures and described 5 possibilities how to motivate students to be active learners. The qualitative analysis of students'feedback is in the end of article. Students appreciated most using ICT tools for instant feedback during lectures and the fact that they had an option to be active.
\end{abstract}

Keywords: university teaching; large lectures; active learning. 


\section{Introduction}

Active learning urges students to be participants in the learning process, requiring them to think about the course material rather than to passively sit and listen. It consists of short content related individual or small-group activities that all students in a class are called upon to do, alternating with instructor-led intervals in which student responses are processed and new information is presented (Felder, Brent). It activates all students rather than just the few who choose to ask questions, volunteer answers or pursue a dialogue with the instructor.

\section{Empirical evidence for active learning}

There has been rising empirical evidence suggesting that active learning is beneficial for students. Most data come from experimental designs of teaching. Hake (1998 in Prince, 2004), in his study of more than 6,000 students, examined pre- and post-test data and found significantly improved performance for students in classes where interactive-engagement methods were used. Active learning also improves acquisition of expert attitudes toward the discipline (Deslauriers, Schelew, Wieman, 2011) and knowledge retention (Graffam, 2007). Baepler, et al., (2016) conducted a study with 41 students who were given a lecture with active learning techniques. These students gained exceeded grade expectations and learned more than their peers in the same course that were taught by classical methods. Brooks (2011 in Baepler et all., 2016) found the same results.

Ruhl, Hughes and Schloss (1987) conducted an experiment with two classes where an experimental group was taught with the so called "two minutes brake" and the controlled group was taught using a straight lecture. Two minutes brakes were used as an active learning technique periods of discussion or note taking at least three times during lecture. According to Rowe (1983 in Ruhl, Hughes and Schloss, 1987) this helps students to assimilate new information. Students in experimental group scored significantly higher in free recall of facts and performance on objective tests. One of the reasons why active learning methods are effective is that they break lectures into smaller parts. As we know, attention spans drop after 15-20 minutes.

Although we have vast evidence of effectiveness in active learning, traditional passive methods of teaching are still widely used, especially in big classes. Some teachers report resistance from students toward active learning techniques (Henderson, Dancy and Niewiadomska-Bugaj, 2012 in Deslauriersa, McCartya, Miller, Callaghana, Kestina, 2019). Richard M. Felder (2013), a great promoter of active learning explained that he lectured around $60 \%$ of the lesson, then made use of activities based on active learning. Active learning methods are not self generating. These activities need be connected with learning objectives that require additional planning by often trial and error techniques. 


\section{Safe environment}

For learning, and especially active learning, it is necessary to establish a safe climate in the classroom. A safe climate can be understood as a place where students feel welcomed, can demonstrate their attitudes and ideas and can make mistakes. Graham and Gisi (2000) claim that classroom climate predicts students's satisfaction. Wilson and Ryan (2013) claim that rapport between students and teachers leads to numerous positive student outcomes, including better attitudes toward the teacher and course, higher student motivation, and perceived learning. Supportive teachers and supportive classmates increase academic efficacy and academic engagement no matter the size of the class (Rosenfeld, Richman, \& Bowman, 2000 in Barr, 2016). According to Barr (2016) students believe that their learning is enhanced through personal interaction both with teachers and other students. Richmond, Berglund, Epelbaum and Kelin (2015) found that instructor rapport accounted for 54\% of the variance in end-of semester student ratings of instruction.

We can establish a safe climate by taking two different approaches into account: 1 . building teacher-student rapport: teachers should reduce anonymity by introducing their professional interests and passions. In addition, it is important to provide information about courses and lectures. 2. building student-student rapport: using icebreakers set the tone for future lessons. Students should have the opportunity to also express their interests in the subject matter.

\section{Tandem teaching}

We see tandem teaching (or co-teaching) as one method to enrich teaching. Students $(\mathrm{N}=372)$ positively rated having two different knowledge bases on a current topic (Heck, 2011). Villa, et al., (2008 in...) found that tandem teaching is beneficial for students because it enables academic improvement and develops a greater sense of community. Tandem teaching helps to deliver more creative lessons with model dialogues where both experts can acknowledge their point of view on one theme. Teachers serve as a good model of cooperation and expert dialogue. Different opinions of both teachers that are based on different expertise engages a diversity of ideas.

\section{Experience analysis}

The authors of this article have a dual role at university. The first is the education of prospective teachers in the pedagogical-psychological component of teacher training. Their second is to educate academics from different disciplines and faculties of the University in a relatively new program for the development of pedagogical competences. This role of curriculum creators and lecturers in academic teaching then in turn influences their own concept of teaching at university. A detailed examination of our own practice then becomes 
both a suitable resource for teaching academic staff and an impetus for our own teaching innovation. We focus on lectures in large groups, which are traditionally most influenced by rigid approaches in understanding the activities of teachers and students. In the following section we introduce five areas of innovation in our own teaching that are in line with the five basic principles of effective teaching at university.

\subsection{Learning goals}

It is essential to plan a course syllabus with learning goals and outcomes. We agree with Biggs \& Tang (2011) that all innovation of instruction should begin and start with identifying the learning goals and outcomes. For example: the goal of this course is for students, in pedagogical context, to be able to characterize basic didactic terms. Students should be able analyze model learning situations. Furthermore, students should be able to explain the procedure of planning, implementation and evaluation of instruction with professional arguments.

We also set learning goals for every lecture. These goals are set to be achievable, measurable and realistic. Here is an example of one lecture: at the end of today's lecture you should be able to: one, recognize properly formulated learning objectives; two, explain and demonstrate the importance of cognitive, affective and sensorimotor goals in education; and three, compare the difficulty of three cognitive learning objectives. These goals are presented at the beginning of every lecture. Students are asked if they already understand these goals. They should then read the goals and show by hand how who understands them. The procedure is easy - palm on the desk means that they do not know anything about the theme (goal), palm highest as possible means that they already understand this goal.

At the end of the lecture students are asked again. We have two reasons for doing so: one, students can think about the lecture and learning goals (it helps fit it into memory); two, we have feedback about students' understanding of the lecture.

\subsection{Assignment}

We agree that the final exam should be well planned from the beginning of the course and in close compliance with its goals, content and learning instruction; however, the "perfect" test is still in the creative process. Nowadays test consist open ended and close ended and questions (wit 0-3 right answers). Test consists of questions with lower and higher order thinking skills where own analysis of learning situation and argumentation of right choice is necessary. As an example, we can show one open ended question: "Write two learning goals of your future class according to your studied field." This question control the capability of setting learning goals and ability to apply this information to the students' field. 


\subsection{Co-teaching}

Authors of this article have had 3 years experience with co-teaching in the course for academics. These courses were positively rated by academics. We also felt the courses were quite successful; therefore, we wanted to try this teaching method in a bigger group of students. It is important to note that both of us have a different professional background. One of us holds a Ph.D. in pedagogy with a masters in chemistry and the other one is holds a Ph.D. in educational psychology. This enables us to explain teaching and learning in a more profound way.

The course were divided into 12 weeks which means we had 12 lectures $(1$ lecture $=1,5$ hour). Eight of the lectures were lead by the pedagogue, two were lead by the psychologist and one lecture was lead of the deputy director of a basic school. One special lecture was taught in tandem by the authors. The theme of the tandem lecture was "How to motivate students during a school lesson?". We divided the themes of each lecture and, when we felt it necessary, the other one added important (or missing) information from their specialisation.

\subsection{Activating students during lectures}

\section{Introduction}

We feel that the most important lessons are the first two. The first lecture in particular should serve as a model of communication and style of work with students. In big lecture halls students are especially not used to working actively during the lecture; therefore, it is important to gradually prepare them for this style of teaching (and learning). We start with introducing ourselves and our course. We feel the introduction should start in a friendly way: we not only say who we are and what we teach but also why. We try to promote our interest and therefore spread our passion for teaching to our students. Students get the information about the course, test and voluntary tasks in e-learning. the first activity is the measurement of the learning goals of forthcoming lecture (see part 3).

\section{Short assignments during lecture}

Students are asked to do a mini assignments during the lecture. These assignments have more purposes than only activation: 1. assignments that induces prior knowledge: for example, in the beginning of the lecture about motivation we ask students "Why do pupils learn?" Students discuss this question in pairs and come up with reasons for learning. 2. checking of understanding: instead of asking students questions "Do you understand? Is there anything you don't understand? etc." we have mini assignments. For example, we ask students to apply theory to real life situations, e.g., how does one best motivate another to learn a new language? We then give them four possible answers to choose from. 


\section{Using practical examples}

We always have our target group in mind: teachers or future teachers. When we try to apply theory to everyday situations, we choose situations with a higher probability of future occurrences. We are aware of examples that are not connected to real life situations and try to avoid them. For example, when we teach about classical conditioning in learning, we talk about pupils in classes, not drooling, Pavlovian dogs.

\section{Using different types of motivation}

Often in academia, motivation is spoken of loosely and applied generally. We say teachers should promote motivation in their students, students should be motivated for learning, etc. Our question is more focused: how does one promote motivation in large-enrollment courses through activation methods? However, it's quite well understood that not all students can be motivated by one method. Therefore, lectures should look to multiple sources of motivation. We tried to involve three types of motivation: achievement, social and cognitive. 1. Social motivation is actualised with co-operation activities. We often use the "write-pair-share" method or a discussion in pairs (mini group work). In addition, one should assume that there are some students who will be reluctant to cooperate. 2. Cognitive motivation can be actualised by solving problem based activities, or by discussing tasks with ambiguous solutions. The main goal need not be to find one right solution, but rather, more importantly, to discuss the process of finding a solution and to formulate expert argumentation. 3. Achievement - we use assignments with only one right answer. Students who want to be good (or best in the classroom) want to know if they are right, not just partially right.

\subsection{E-learning and activities outside of a classroom}

For those who want to learn more, be creative, or get extra points for an assignment, we prepare three activities with an option to get 7 additional points out of 100 maximum achievable in the exam. These three activities are: one, Mind Map of an interesting theme from didactics or educational psychology; two, analysis of taught class; three, turn in notes that are taken during the class. We also provide presentations for students. These presentations are in e-learning but students can obtain them only after lessons. Presentations are considered as help for students, not as a study material. There are also additional materials: articles, videos, etc. Motivated students can have more information, students who don't understand the material have multiple avenues to study more.

\section{Students' feedback.}

The following section consists of students' feedback that was collected by survey and direct written feedback from the last two semesters. 
First semester's quantitative feedback:

Our first attempt in making the course more active for students was voluntarily rated by 24 out of 178 students. This feedback is official feedback that Charles University uses for rating all courses. Firstly, students have to rate the course on a scale where $0 \%$ means "very bad" and $100 \%$ is "completely unique". Our average course rating was $90.19 \%$. Secondly, students had to rate the following statement: "Forms and methods of teaching were chosen purposefully with regard to the nature of the subject." Students rated on a scale from 1 to 4 where $1=$ totally agreed and $4=$ totally disagreed. Our average rating was 1.22.

Second semester's quantitative feedback:

Official feedback has not been collected yet for this semester. As we know from our previous semester, this official feedback is not completed by a lot of students. From our experience, only extremely satisfied and extremely dissatisfied students rate courses. Because of this, we decided to collect our own feedback at one of the last lectures. Students were asked to anonymously write down on one side of paper positives (what they appreciate) and on the other side negatives (what should have been better) of the course. We got a total of 52 student responses.

\section{Qualitative feedback}

In the following we devote to the feedback as analyzed by the MAXQDA program. We rewrote these statements, gave them code and categorized these codes in research categories. In the following we explain these categories and cite some students'statements, written in italics. Most statements (32) were in the category "using ICT tools for instant feedback". Students appreciated new methods in teaching, fourteen statements explicitly wrote about using "Kahoot", twelve wrote that they liked "Plickers" and one statement was about liking "Sketchnoting". Five of the statements were general (using ICT, showing us how to work with ICT). It was said that these techniques "varied within the lecture". The second most used category, with 28 student responses, was "activization of students". The typical statement was (paraphrasing): "Students had the opportunity to engage in interesting ways." Six times students wrote about the dialogic lecture". Seventeen statements were thematically connected with co-teaching. Six statements thematized the diversity: "not only thematic but also taught from a variety of diverse points of view." Two people wrote that they liked co-teaching because of "more varied teaching", one student saw a positive in "more specialized teachers".

Eleven statements were about the instructors. Students wrote that we were "nice", "had a positive attitude", had "nice behavior" and it was a "positive climate thanks to the teachers". Eleven people wrote that our course was useful. For 9 people, presentations were important, especially when they were "brief", "available" and "good". Six 
statements were put into the category "course in general": "interesting lectures" $(5 \mathrm{x})$. We were glad to read this feedback: "please teach like this - whoever attended the class always looked forward to it". Four people liked examples that "were connected to practise", "ilustrative" and "practical". Four people liked that we were using a microphone. Three people appreciate that we put materials in e-learning. Three students said that the content of the course was great (especially formative feedback). Two students noted that they liked the idea of voluntarily activities because it helped them "not to be so stressed for the final exam".

We especially appreciated the feedback from one student in particular: "This course is suitable also for teachers who have had many years of experience. I was very interested in the goals of learning that can be very helpful to the teacher in focusing on their pupils' work. Knowledge of effective strategies is also beneficial to practice. Personally, I gradually included the information I learned in the class into my own teaching. Pupils are more involved in the lessons. They are motivated, well informed about the subject matter and are willing to cooperate and feel comfortable in the lessons. The disadvantage, however, is the slow progress. On the other hand, it is balanced by a deeper understanding and real practical use of the information."

\section{Conclusion}

Our jobs as college professors can be exciting and beautiful. At the same time, it is an activity that requires great knowledge and skill in the areas of cognitive and social psychology, pedagogy, didactics as well as current knowledge from the latest research applied to effective teaching strategies. We see the necessity of changing traditionally taught large-enrollment courses into courses with more active learning environment for students.

We understand that these methods and techniques may not be the expertise of all academics. However, since it is our area of expertise and experience, we feel an added obligation to not only make it a further focus of our research to teach to others but also to implement these methods and techniques into our own classes unrelated to this focus. It is important to have the courage to try new ways of approaching students, overcome fear or failing and spending more time of creating effective lectures. After reap the rewards of your hard work, students get more active and come with their own ideas. Not only students learn new information but also we as a teachers get more from lectures.

Our findings have shown that active teaching methods are appreciated by students in the large lecture hall setting and seem to be congruent with the previosly cited Hake, et al., (1998 in Prince, 2004) study claiming that "active learning is beneficial for students". Verification research design with an experimental and control group seems the best way 
how to add an important value to our further research. We also hope to further solidify our findings with continued applications to our courses.

\section{References}

Appert, L., Bean, Ch.S., Irvin, A. et all. (2018). Guide for Inclusive Teaching at Columbia. Columbia

Barr, J.J. (2016). Developing a Positive Classroom Climate IDEA Paper \#61.

Baepler, P., Walker, J. D., Brooks, Ch., Saichaie, K., Petersen, Ch. I. (2016). A Guide to Teaching in the Active Learning Classroom: History, Research, and Practise. Sterling, Virginia

Biggs, J., \& Tang, C. (2011). Teaching for quality learning at university: What the student does. Maidenhead \& New York: Society for Research into Higher Education \& Open University Press.

Deslauriers, L., Schelew, E., Wieman, C. (2011), Improved learning in a large-enrollment physics class. Science 332, 862-864.

Deslauriersa, L, McCartya, L.S., Millerc ,K., Callaghana, K., Kestina, G. (2019) Measuring actual learning versus feeling of learning in response to being actively engaged in the classroom. PNAS, vol 116, n. 39

Graffam B. (2007)Active learning in medical education: strategies for beginning implementation. Med Teach.;29(1):38-42.

Felder, R. (2013). You got questions, we got answers 2. Active Learning. Chemical Engineering Education, 47(2), 97-98

Felder, R., Brent, R. (2009) Active learning: An Introduction. ASQ Higher Education Brief August 2009

Heck, T. (2011). Co-Teaching In Higher Education. Journal of College Teaching and Learning. Vol. 5. n. 3.

Prince, M. (2004). Does Active Learning Work? A Review of the Research. Journal of Engineering Education 93(3)

Ruhl, K., Hughes, Ch.A., Schloss, P.J. (1987). Using the Pause Procedure to Enhance Lecture Recall. Teacher Educationa and Special Education 10(1)

Wilson, Janie H., Rebecca G. Ryan. 2013. "Professor-Student Rapport Scale: Six Items Predict Student Outcomes." Teaching of Psychology, 40 (2): 130-133. doi: 10.1177/0098628312475033

https://digitalcommons.georgiasouthern.edu/psych-facpubs/16 